\title{
A EDUCAÇÃO BÁSICA E SUAS CONTEXTUALIZAÇÕES: A TECNOLOGIA E A ESCOLA DO CAMPO ${ }^{1}$
}

\section{Basic Education and its Contextualizations: Technology and the Field School}

\author{
Andrieli Dal Pizzol ${ }^{2}$ \\ Jamile Santinello ${ }^{3}$
}

\begin{abstract}
Resumo: O presente artigo reflete sobre as contextualizações da Educação Básica e a inserção das tecnologias educacionais nos currículos das escolas do campo. Assim, pauta-se no objetivo central de refletir sobre o uso das tecnologias na educação do campo, no município de Pitanga$\mathrm{PR}$, enfocando nos pontos críticos a esse respeito, tanto nas escolas rurais como nas urbanas. Desse modo, aborda-se sobre conceitos e leis que versam sobre o direito à educação para os alunos dessa etapa educacional, com perspectivas tanto para os estudantes da zona urbana, como da zona rural. Apresenta-se ainda algumas questões voltadas à Educação Infantil para crianças de 4 a 5 anos de idade, matriculadas na pré-escola, além de explorar os dados e informações dos anos iniciais do Ensino Fundamental. Para tanto, optou-se pela pesquisa qualitativa, desenvolvida em forma de estudo de campo, revisão bibliográfica dos temas trabalhados e análise dos dados.
\end{abstract}

Palavras-chave: Educação Básica. Tecnologias. Escola do Campo.

\begin{abstract}
This article reflects on the contextualization of Basic Education and the insertion of educational technologies in the curricula of rural schools. Thus, it is guided by the central objective of reflecting on the use of technologies in rural education, in the municipality of Pitanga-PR, focusing on the critical points in this regard, both in rural and urban schools. In this way, it deals with concepts and laws that deal with the right to education for students in this educational stage, with perspectives for students in both urban and rural areas. It also presents some questions related to Early Childhood Education for children from 4 to 5 years old, enrolled in pre-school, in addition to exploring data and information from the early years of Elementary School. To this end, we opted for qualitative research, developed in the form of a field study, bibliographic review of the themes worked and data analysis.
\end{abstract}

Keywords: Basic Education. Technologies. Countryside School.

\footnotetext{
${ }^{1}$ Este texto apresenta parte de estudo desenvolvido em dissertação de mestrado de um dos autores, aprovado pelo Comitê de Ética em Pesquisa, COMEP-UNICENTRO, número do parecer 18286119.3.0000.0106 em 06/09/2019.

${ }^{2}$ Mestra em Educação pela Universidade Estadual do Centro-Oeste (UNICENTRO); Professora colaboradora no Departamento de Pedagogia (DEPED) na Universidade estadual do centro-Oeste (UNICENTRO). ORCID: 00000002-4878-476X. E-mail: andrielidp@gmail.com

${ }^{3}$ Doutora em Comunicação- UFRJ, Docente efetiva da Universidade Estadual do Centro-Oeste - UNICENTRO Departamento de Pedagogia-DEPED/G; Docente do Programa Pós-Graduação em Educação - Mestrado em Educação. ORCID: https://orcid.org/0000-0003-1136-2421. E-mail: jamilesantinello@gmail.com.
} 


\section{Introdução}

Este artigo visa debater a organização da Educação Básica, enfatizando os dispositivos legais que asseguram o processo educativo no país, como, por exemplo, a Lei de Diretrizes e Bases da Educação Nacional n. 9.394/1996, a Constituição Federal de 1988, o Plano Nacional de Educação, entre outras. Além disso, são apresentados os dados registrados pelo Instituto Nacional de Estudos e Pesquisas Educacionais Anísio Teixeira - INEP, referente ao ano de 2018, com o objetivo de explorá-los em relação ao comparativo entre Brasil e o município de Pitanga/PR, onde foi desenvolvida a pesquisa de Mestrado em Educação. Os dados fazem menção às matrículas da Educação Básica, desde a Educação Infantil até o Ensino Médio de escolas urbanas e rurais.

A reorganização da Educação Básica é um tema que precisa ser debatido a partir de uma perspectiva geral, a fim de se compreender a importância da educação e como ela é tratada no Brasil, um país que dispõe de uma vasta quantidade de escolas espalhadas por todo o seu território ${ }^{4}$. Essas instituições, situadas em zonas urbanas e rurais, possuem grandes diferenças nos métodos de ensino e em sua infraestrutura, sobretudo quanto ao uso das Tecnologias Digitais da Informação e Comunicação (TDIC).

A Educação Básica brasileira é obrigatória e gratuita dos 4 até os 17 anos, período que compreende a pré-escola, o Ensino Fundamental, dividido entre anos iniciais e anos finais, e o Ensino Médio, conforme o disposto no Art. $4^{\circ}$ da Lei de Diretrizes e Bases da Educação Nacional (LDBEN) 9.394/96. O Art. $2^{\circ}$ da mesma lei traz o seguinte: "A educação, dever da família e do Estado, inspirada nos princípios de liberdade e nos ideais de solidariedade humana, tem por finalidade o pleno desenvolvimento do educando, seu preparo para o exercício da cidadania e sua qualificação para o trabalho.” (BRASIL, 1996).

Neste contexto, entende-se que a educação engloba pleno desenvolvimento da pessoa, o preparo para o exercício da cidadania e sua qualificação para o trabalho, formando uma tríade inspirada pelos princípios de liberdade e dos ideais de solidariedade humana (BRASIL, 1996). De acordo com Cury (2008), o conceito de Educação Básica vem para esclarecer e administrar as ações realizadas em busca de um novo espaço público, assim, "resulta daí que a Educação Infantil é a raiz da Educação Básica, o Ensino Fundamental é o seu tronco e o Ensino Médio é seu acabamento. É dessa visão holística de base e básica que se pode ter uma visão consequente das partes" (CURY, 2008, p. 295).

Logo, compreende-se que a Educação Básica é um dos fundamentos principais da educação no país e, para que seja contemplada em todas as suas especificidades, é necessário um corpo docente preparado para atender às demandas de uma sociedade em constante transformação. Sobre o assunto, Silva e Camargo (2015, p.169) afirmam que "[...] não podemos esquecer que a atividade educativa é, antes de tudo, uma manifestação cultural e, portanto, constitui-se ao longo do tempo por meio de rupturas, mudanças e transformações sociais, políticas e econômicas."

Assim sendo, a ação educativa está totalmente vinculada aos valores, às ideias, às tradições e aos costumes de cada população. A Constituição Federal do Brasil de 1988 assegura, em seu Art. 205, a educação como direito do cidadão e dever do Estado. Em complemento, a LDBEN 9.394/96, dentre seus artigos e incisos, estabelece os objetivos, princípios e fundamentos necessários para que os governos cumpram com a tríade educativa.

\footnotetext{
${ }^{4}$ Observa-se os dados retirados Censo Escolar em que:” O Brasil conta, em 2019, com 180.610 escolas de educação básica. Desse total, a rede municipal é responsável por aproximadamente dois terços das escolas (60\%), seguida da rede privada (22,9\%)" (INEP, 2019, p.12).
} 
Na Constituição Federal de 1988 (CF 88), art. 214º, o Plano Nacional de Educação (PNE) é destacado:

[...] com o objetivo de articular o sistema nacional de educação em regime de colaboração e definir diretrizes, objetivos, metas e estratégias de implementação para assegurar a manutenção e desenvolvimento do ensino em seus diversos níveis, etapas e modalidades por meio de ações integradas dos poderes públicos das diferentes esferas federativas que conduzam a:

I - erradicação do analfabetismo;

II - universalização do atendimento escolar;

III - melhoria da qualidade do ensino;

IV - formação para o trabalho;

V - promoção humanística, científica e tecnológica do País.

VI - estabelecimento de meta de aplicação de recursos públicos em educação como proporção do produto interno bruto (BRASIL, 1988).

Dentre tais objetivos, destaca-se o inciso $\mathrm{V}$, que trata da promoção humanística, científica e tecnológica no país, na busca de garantir a formação do sujeito de maneira integral e vinculada à nova perspectiva de sociedade da era moderna, ou seja, ligada ao avanço da tecnologia em todos os setores da sociedade. Cabe destacar também o que afirma o inciso IV, sendo necessária ações do Estado no sentido de oferecer uma formação para o trabalho. Para que tudo isso seja alcançado, é necessário que o inciso VI seja cumprido, de modo a possibilitar o financiamento necessário para se obter uma melhoria constante da educação no país, propiciando maior qualidade no serviço educacional de maneira igual para toda a população.

O desenvolvimento da Sociedade do Conhecimento - compreendida pela mudança em compreender o mundo, com ênfase na ciência - que visa a mudança de ação frente às demandas sociais, perpassa pelo entendimento de que o movimento tecnológico é constante e exige uma nova concepção sobre o processo de ensino-aprendizagem (SANT'ANA; BEHRENS, 2003). Corroborando com essa ideia, Valente $(1999$, p. 29) afirma que:

\begin{abstract}
O conhecimento e, portanto, os seus processos de aquisição assumirão papel de destaque, de primeiro plano. Essa valorização do conhecimento demanda uma nova postura dos profissionais em geral e, portanto, requer o repensar dos processos educacionais, principalmente aqueles que estão diretamente relacionados com a formação de profissionais e com os processos de aprendizagem.
\end{abstract}

Essa mudança no setor da educação acontece lentamente, legitimando a ideia de que os processos educativos não conseguem acompanhar as mudanças tecnológicas que ocorrem na sociedade. No ano de 2014, foi aprovada e sancionada a Lei n. 13.005/2014 $4^{5}$, o Plano Nacional de Educação - PNE, propondo vinte metas a serem cumpridas no prazo de 10 anos. No seu artigo $2^{\circ}$, são definidas as diretrizes que regem o planejamento para a educação nacional, dentre as quais destacam-se: "IV - melhoria da qualidade da educação. VIII - Promoção humanística, científica, cultural e tecnológica do País" (BRASIL, 2014).

Em sua sétima meta, o PNE traz a seguinte meta: "Fomentar a qualidade da Educação Básica em todas as etapas e modalidades, com melhoria do fluxo escolar e da aprendizagem de modo a atingir as seguintes médias nacionais para o IDEB” (BRASIL, 2014). Além disso,

\footnotetext{
${ }^{5}$ Cabe mencionar o PNE (2001-2010), que antecedeu o PNE vigente. Para saber mais, acesse Portal do Ministério da Educação.
} 
também são apresentadas as medidas propostas para os anos compreendidos entre 2015 a 2021, bem como as estratégias para que a referida meta e suas respectivas médias sejam alcançadas. Para tanto, destacam-se os seguintes procedimentos:

7.12) incentivar o desenvolvimento, selecionar, certificar e divulgar tecnologias educacionais para a educação infantil, o ensino fundamental e o ensino médio e incentivar práticas pedagógicas inovadoras que assegurem a melhoria do fluxo escolar e a aprendizagem, assegurada a diversidade de métodos e propostas pedagógicas, com preferência para softwares livres e recursos educacionais abertos, bem como o acompanhamento dos resultados nos sistemas de ensino em que forem aplicadas;

7.20) prover equipamentos e recursos tecnológicos digitais para a utilização pedagógica no ambiente escolar a todas as escolas públicas da educação básica, criando, inclusive, mecanismos para implementação das condições necessárias para a universalização das bibliotecas nas instituições educacionais, com acesso a redes digitais de computadores, inclusive a internet; (BRASIL, 2014, META 7; 7.12;7.20).

Assim, é evidente que uma das metas para a educação nacional é aumentar o uso de tecnologias educacionais no desenvolvimento de práticas pedagógicas e metodológicas, com a inserção de recursos e equipamentos para a promoção de uma Educação Básica que atenda as demandas sociais. Desse modo, ao analisar a LDBEN 9.394/96, juntamente com o PNE, entende-se que tais leis buscam garantir uma educação pública gratuita e de qualidade, proporcionando o pleno desenvolvimento do sujeito, o que perpassa pela utilização das tecnologias.

Sant'Ana e Behrens (2003) destacam que o desafio para os próximos anos será conseguir que crianças e jovens, imersos nas transformações ocorridas pela Sociedade do Conhecimento, possam descobrir o sentido da ética, da cidadania e da vida plena. As autoras ainda ressaltam que a escola precisa oferecer uma educação que contemple o sucesso ao invés do fracasso, sendo necessário formar os alunos para o futuro, já que, cada vez mais, é necessária a especialização de profissionais em determinada área de conhecimento, além de uma visão generalista de sua profissão.

A Sociedade do Conhecimento requer certa autonomia na tomada de decisões e, para isso, o currículo escolar deve passar por modificações, incluindo atividades individuais e grupais onde a tecnologia faça parte do cotidiano escolar, proporcionando o aprendizado significativo e prazeroso aos alunos (VALENTE, 1999).

Para tanto, as instituições escolares precisam inovar, a fim de acompanhar as evoluções socais, percebendo que essa evolução enseja mudança nos processos formativos. Embora as tecnologias digitais não sejam a solução para todos os problemas enfrentados pelas instituições de ensino brasileiras, elas surgem como algo desafiador e motivador, possibilitando que o aprendizado transcenda os muros escolares.

Moran (2013) relata que uma boa escola necessita de professores motivados, criativos, mediadores, seja on-line ou off-line, e que apresentem aulas inovadoras, interativas, com experimentos e pesquisa. Ou seja, uma instituição de qualidade deve buscar meios para potencializar as redes de aprendizagem entre os professores e os alunos, para que possam aprender juntos, de modo colaborativo. 
conservador, a internet é utilizada para controlar mais os alunos, para reforçar o papel do professor como mero transmissor de conhecimentos. O mais importante é o que a escola faz, como ela se organiza, as relações entre gestores, docentes, alunos e comunidade. Não há tecnologias avançadas que salvem maus profissionais (MORAN, 2013, p. 27).

Essa transformação educacional não depende apenas do corpo docente, mas também deve ser apoiada pelos os alunos, funcionários, equipe pedagógica e até mesmo o núcleo familiar dos estudantes, já que com apoio afetivo e estímulos adequados, eles conseguem aprender com maior facilidade e tornam-se mais confiantes (MORAN, 2013).

Para além dessas mudanças, é preciso considerar que os professores formados de modo apenas a cumprir uma formação em nível superior, sem levar em consideração o que sua profissão faz, acarreta em prejuízos para todos os envolvidos em seu processo. Assim, o currículo formativo deve pensar na formação crítica, política e emancipatória dos futuros professores, sobretudo para aqueles que querem exercer a docência.

É importante reavaliar os currículos escolares, pautando-se nos anseios advindos das tecnologias e suas implicações, entretanto, essa mudança também deve ocorrer no âmbito discente, buscando motivar os alunos e despertar sua curiosidade durante o processo de aprendizagem. Atividades motivadoras, instigantes, como as de pesquisa e de prática, proporcionam o maior envolvimento dos estudantes, o que, consequentemente, aumenta o interesse e a interação dos alunos com os conteúdos ministrados.

Sobre o assunto, Moran (2013, p. 28) destaca que "aprendemos mais quando estabelecemos pontes entre a reflexão e ação, entre a experiência e a conceituação, entre a teoria e prática; quando ambas se alimentam mutuamente". A aprendizagem se consolida quando o sujeito consegue equilibrar e integrar os seus sentimentos e razões, estabelecendo objetivos e, não menos importante, interagindo com as demais pessoas.

\begin{abstract}
A educação escolar precisa compreender e incorporar mais as novas linguagens, desvendar os seus códigos, dominar as possibilidades de expressão e as possíveis manipulações. É importante educar para os usos democráticos, mais progressistas e participativos das tecnologias, que facilitem a evolução dos indivíduos (MORAN, 2013, p. 53).
\end{abstract}

Importante enfatizar que a educação é realizada também pela família, a qual necessita de uma rede de apoio para que possa incentivar a aprendizagem das crianças desde o nascimento e, dessa forma, quando estas chegarem à instituição escolar, os processos de aprendizagem básicos já estarão internalizados.

Silva e Camargo (2015, p. 170) ressaltam que a conjectura da natureza da escola é cultural, onde "qualquer análise do panorama educacional nacional ou internacional parte necessariamente da consideração do contexto cultural em que a comunidade escolar está inserida". Neste ínterim, a cultura constitui-se como uma das principais circunstâncias da vida humana, construindo uma base sólida das relações sociais que são estabelecidas no ambiente escolar.

As tecnologias podem ser consideradas como formas de comunicação e expressão, estando extremamente presentes no cotidiano social. Por mais que a educação ainda não tenha incorporado completamente seus usos e explorado de maneira assertiva os seus recursos, devido à tradicionalidade do processo de ensino, elas vêm como uma forma de avigorar o processo 
formativo do sujeito. Para isso, torna-se necessário compreender melhor estas etapas da educação (VALENTE, 2014).

Em consonância, Silva e Camargo (2015, p. 173), afirmam que:

\begin{abstract}
Até hoje, a escola se posicionou de maneira um tanto refratária e adversa às transformações da pós-modernidade. Todavia, nos últimos anos, a aceleração do desenvolvimento tecnológico tornou inevitável o confronto da escola com a cultura digital, em função do como esta afeta a interação entre as pessoas, os processos de comunicação e a produção e a transmissão de conhecimento.
\end{abstract}

A partir dessas considerações, é possível afirmar que a tecnologia digital é uma parte fundamental da cultura escolar contemporânea, permeando a vivência dos professores, dos alunos e da comunidade escolar, por meio da interação resultante do uso da internet. Sendo assim, torna-se relevante discutir com profundidade sobre a constituição do ensino público e, para tanto, o presente artigo foi subdividido em dois momentos: o primeiro, que oportuna compreender a organização da Educação Básica no ambiente da escola do campo, e o segundo momento, apresentando o olhar voltado à Educação Infantil (4 a 5 anos) e aos anos iniciais do Ensino Fundamental. O item a seguir discute a Educação Básica sob a perspectiva da escola do campo, sua organização e demanda, refletindo como o espaço do campo oportuniza conhecimentos.

\title{
2 A educação básica na perspectiva da escola do campo
}

As escolas municipais e estaduais do campo, presentes em todo o Brasil, possuem características distintas das escolas urbanas, uma vez que a localização de cada instituição reflete os modos de vivência de cada região, levando em consideração as suas crenças e perspectivas de vida. Arroyo e Fernandes (1999) apontam que a escola do campo tem como papel fundamental, a busca por equidade nos processos formativos de seus alunos, a fim de oferecer um ensino igual ao das zonas urbanas, em conjunto com formações que visam enriquecer a produtividade do campo. Assim, Caldart (2009, p.38) reflete que é necessário

[...] compreender este fenômeno chamado de Educação do campo em sua historicidade, o que implica buscar apreender as contradições e tensões que estão na realidade que a produziu e que a move, e que ela ajuda a produzir e mover; que estão no 'estado da coisa', afinal, e não apenas nas ideias ou entre ideias sobre o que dela se diz.

Segundo a autora, a Educação do Campo movimenta-se sempre em caminhos difíceis, em sua luta e busca por condições de acesso, permanência e manutenção. Para além de um projeto constitutivo, não é só na escola que o conhecimento deve ser adquirido, mas sim, na junção da escola e da comunidade rural.

Arroyo e Fernandes (1999) salientam que há dois fatores para a Educação Básica e o movimento social do campo. O primeiro é a real existência de um movimento social do campo e, o segundo, refere-se a um movimento pedagógico. Esses dois fatores estão aliados em busca de uma educação que contemple os dispositivos legais, 
[...] outra compreensão e prática da educação básica: a escola rural tem que dar conta da educação básica como direito do homem, da mulher, da criança, do jovem do campo. Ou seja, estamos colocando a educação rural onde sempre deve ser colocada, na luta pelos direitos. A educação básica, como direito ao saber, direito ao conhecimento, direito à cultura produzida socialmente (ARROYO; FERNANDES, 1999, p. 11).

Assim, é possível dizer que a Educação Básica no âmbito rural é real e a sua ação não pode ocorrer de maneira a apenas copiar o que a cidade produz, mas deve buscar uma formação política, social e emancipatória própria, procurando concretizar as ações de um currículo que atenda a tais objetivos.

A crítica feita por Arroyo e Fernandes (1999) consiste no fato de que os currículos e as políticas educacionais são elaborados para os grandes centros, visando suprir a demanda produtiva da sociedade moderna. A escola rural, no entanto, só é lembrada em situações excepcionais, perdendo a sua identidade - essa considerada como a função social que a escola do campo deve exercer, na continuidade do desenvolvimento do campo, na continuação da atividade rural como sustento de muitas famílias, atrelando o conhecimento científico, em que o sujeito inserido no contexto rural compreenda que a importância de sua permanência e atividades deem continuidade no campo, que a escola vem como meio de fomentar a busca por novos conceitos e pesquisas para enriquecer a atividade rural - com a produção rural.

É curioso constatar que se pensa na escola e na professora rural apenas na sugestão de adaptação dos calendários, flexibilização de conteúdo ou que sejam levados em conta os regionalismos, mas, na verdade, os conteúdos são iguais para todos e o propósito de preparar a juventude do campo e da cidade para o desenvolvimento da produção do mercado são os mesmos.

A educação do campo demonstrou, ao longo dos anos, uma presença maciça de professores oriundos da zona urbana, os quais reproduziam o currículo da cidade na escola rural, tendo em vista a demanda educacional apresentada a partir dos anos de 1960, sem levar em consideração as particularidades que essas instituições apresentam, no intuito de manter a sua identidade.

Com a promulgação da Lei n. 5.692/71, as escolas das primeiras séries do primeiro grau não necessitavam de professores formados no Ensino Superior, pois a formação nos cursos normais já era o suficiente para o exercício da docência. Mesmo a formação no Ensino Superior não oferecia o suporte adequado para os anseios das comunidades rurais, fato que ainda é presenciado nos dias de hoje (VIGHI, 2015).

A partir dessas informações, a elaboração de um projeto de Educação Básica do Campo deve "incorporar um olhar mais rico de cultura e conhecimento, uma visão mais digna do campo, o que será possível se situamos a educação, o conhecimento, a ciência, a tecnologia; a cultura como direitos e as crianças e jovens, os homens e mulheres do campo como sujeitos desses direitos" (ARROYO; FERNANDES, 1999, p. 17). Deve-se pensar em uma proposta que contemple todos os sujeitos envolvidos na comunidade escolar do campo e que possibilite o fortalecimento da vida nessas regiões, melhorando-a e potencializando-a.

Complementando essa afirmação, Caldart (2009, p. 39) diz que "a Educação do Campo nasceu como crítica à realidade da educação brasileira, particularmente à situação educacional do povo brasileiro que trabalha e vive no/do campo". Não se trata de uma crítica à educação, mas sim, na vivência dos trabalhadores do campo, o que está ligado diretamente ao trabalho e resistência dos projetos do campo, que culminam na realidade educacional brasileira. 
Arroyo e Fernandes (1999) argumentam que a estrutura da escola do campo não pode limitar-se apenas às quatro paredes da sala de aula, ao livro e ao quadro de giz, devendo ir além, no sentido de reinventar os tempos e espaços dessa instituição e planejar com perspectivas de melhoria, equidade, oportunidades e permanência no campo. Para tanto, é necessário utilizarse das mais diversas ferramentas, sejam elas tecnológicas ou não, mas com o mesmo objetivo de fomentar o seu desenvolvimento.

$\mathrm{O}$ estudante tem o direito de beneficiar-se das tecnologias, seja na zona urbana ou na zona rural. Assim, "a cultura escolar entra em correspondência com a cultura digital, ou seja, com o modo como as pessoas interagem, produzem conhecimento, aprendem e se comunicam" (SILVA; CAMARGO, 2015, p. 174), disponibilizando estratégias de aprendizagem que estejam em consonância ao acesso, transmissão e produção dos conhecimentos contemporâneos. A LDBEN n. 9.394/96 destaca, em seu Art. 28, a Educação Básica para público rural:

[...] os sistemas de ensino promoverão as adaptações necessárias à sua adequação às peculiaridades da vida rural e de cada região, especialmente:

I - Conteúdos curriculares e metodologias apropriadas às reais necessidades e interesses dos alunos da zona rural;

II - Organização escolar própria, incluindo adequação do calendário escolar às fases do ciclo agrícola e às condições climáticas;

III - adequação à natureza do trabalho na zona rural (BRASIL, 1996).

Embora o artigo não enfatize especificamente sobre o uso das tecnologias para a organização curricular das instituições do campo, entende-se que que sua utilização é necessária para o cumprimento de tais determinações, sendo preciso, portanto, implementar ações para o desenvolvimento de metodologias que possibilitem a sua inserção, a fim de atender as perspectivas do meio rural.

A tradição na formulação de políticas públicas para formação de professores não leva em consideração as especificidades que a educação do campo necessita, sendo que "[...] o sistema escolar é urbano, apenas pensado no paradigma urbano" (ARROYO, 2007, p. 158). A busca por uma democratização do uso, do acesso ao conhecimento e das tecnologias educacionais, perpassa pela inquietação das escolas públicas diante do objetivo de oferecer essas tecnologias aos seus alunos.

As mudanças que veem ocorrendo na sociedade, mediadas pelas tecnologias em rede, implicam, em médio prazo, na reinvenção da educação em todos os níveis e de todas as formas (MORAN, 2013). Neste contexto, o item a seguir explana a descrição da pré-escola e os anos iniciais do Ensino Fundamental, etapas pertencentes à Educação Básica.

\subsection{Da pré-escola aos anos iniciais: do urbano ao rural}

O presente estudo ${ }^{6}$ optou por focalizar suas pesquisas e inquietações na Educação Básica de escolas do campo, com foco nos professores que trabalham desde a pré-escola até os anos iniciais do Ensino Fundamental, e na apropriação de tecnologias digitais e demais instrumentos que fomentem a busca por uma educação de qualidade e igualitária. Para tanto, foi necessário compreender as relações em torno das etapas da Educação Básica, no âmbito urbano e rural,

\footnotetext{
${ }^{6}$ As reflexões aqui apresentadas representam parte de pesquisa de mestrado de uma das autoras.
} 
possibilitando uma visão mais ampla e, em seguida, mais especificamente do estado do Paraná, no município de Pitanga.

De acordo com os dados do Instituto Nacional de Estudos e Pesquisa - INEP, o Brasil apresentou os seguintes valores estatísticos da Educação Básica em relação às matrículas no último censo escolar de 2019:

Tabela 1 - Sinopses da Educação Básica

\begin{tabular}{c|c}
\multicolumn{2}{c}{ SINOPSES ESTATÍSTICAS DA EDUCAÇÃO BÁSICA } \\
\hline BRASIL & 48.455 .867 \\
REGIÃO SUL & 6.504 .063 \\
PARANÁ & 2.601 .677 \\
SANTA CATARINA & 1.579 .175 \\
RIO GRANDE DO SUL & 2.323 .211 \\
\multicolumn{2}{c}{ Fonte: Inep - Censo escolar (2019) }
\end{tabular}

A Tabela 1 apresenta as estatísticas de matrículas realizadas no ano de 2018, na Educação Básica, desde a Educação Infantil até o Ensino Médio. A partir destes dados, podese afirmar que a Região Sul corresponde a 13,42\% do total de matrículas efetuadas no Brasil, sendo que o Paraná $^{7}$ representa 5,37\% do montante, número expressivo em vista do total de matrículas apresentadas pela região, ocupando o primeiro lugar, seguido do estado do Rio Grande do Sul, com 4,79\%, e Santa Catarina, com 3,26\%.

Para compreender melhor as estatísticas de matrículas, é necessário apresentar os dados da cidade em que a pesquisa foi realizada, o município de Pitanga/PR, localizado na região central do estado. O estado do Paraná obteve um total de 714.182 matrículas para a pré-escola no ano de 2018, enquanto o município de Pitanga/PR efetivou 793 matrículas, distribuídas da seguinte forma: 580 para a área urbana, sendo 462 matrículas para a rede municipal, 137 para a rede privada e 213 matrículas para a rede pública rural do município (INEP, 2018).

Já os anos iniciais do Ensino Fundamental representam um total de 781.858 matrículas no Paraná, sendo que no município de Pitanga houve um total de 2.281 matrículas, distribuídas em 1.686 para a área urbana, com 1.331 matrículas para a rede municipal, 355 para a rede privada e 595 matrículas para a rede municipal rural (INEP, 2018).

Verifica-se então, que se trata de um número bem expressivo para a educação do campo, levando em consideração que muitas famílias optam por levar seus filhos até os centros urbanos para dar continuidade aos estudos (PPP, 2019). Esse fenômeno perpassa pela ideia de que uma boa educação somente é encontrada em grandes centros urbanos e em escolas particulares, sendo que muitas famílias acabam por sacrificar toda sua organização para oportunizar o estudo na cidade para seu(s) filho(s), sem mesmo conhecer os planos de ensino, o projeto pedagógico da instituição do campo que atende sua localidade.

Neste ínterim, os próximos itens abordam especificamente a Educação Infantil, compreendendo o período da pré-escola para crianças de 4 a 5 anos de idade e os anos iniciais do Ensino Fundamental, do $1^{\circ}$ ao $5^{\circ}$ ano, correspondendo as etapas de ensino em que a pesquisa foi realizada na instituição de ensino, alvo do estudo.

\footnotetext{
${ }^{7}$ Deve-se observar que o estado do Paraná é o maior em população, influenciando na quantidade de matrículas.
} 
2.1.1 Um olhar para a educação infantil (4 e 5 anos) e para os anos iniciais do ensino fundamental

$\mathrm{O}$ atendimento em creche e pré-escola é um direito assegurado pela Constituição Federal de 1988 e pela LDBEN 9.394/96, para crianças de zero a cinco anos de idade. Cabe salientar que a Educação Infantil se tornou obrigatória para crianças de 4 e 5 anos por meio da Emenda Constitucional n $n^{\circ}$ 59/2009, que estabelece a obrigatoriedade da Educação Básica dos 4 aos 17 anos.

A Educação Infantil, primeira etapa da Educação Básica, é a base do processo educacional e, muitas vezes, representa a primeira separação das crianças de seu convívio familiar. Apoiadas na concepção do cuidar e do educar, as instituições escolares de Educação Infantil não são apenas espaços de cuidados para com as crianças, mas também constituem importante etapa para o pleno desenvolvimento dos sujeitos que ali estão inseridos, conforme explicitado na Base Nacional Comum Curricular - BNCC:

\begin{abstract}
Nesse contexto, as creches e pré-escolas, ao acolher as vivências e os conhecimentos construídos pelas crianças no ambiente da família e no contexto de sua comunidade, e articulá-los em suas propostas pedagógicas, têm o objetivo de ampliar o universo de experiências, conhecimentos e habilidades dessas crianças, diversificando e consolidando novas aprendizagens, atuando de maneira complementar a educação familiar (BRASIL, 2018, p. 36).
\end{abstract}

No que tange à legislação vigente da Educação Infantil, destacam-se as Diretrizes Curriculares Nacionais da Educação Infantil - DCNEI, pertencentes às Diretrizes Curriculares Nacionais da Educação Básica - DCNEB, que trazem as orientações, os procedimentos e as instruções para esta etapa educacional. Dentre tais diretrizes, destaca-se o disposto em seu Art. $4^{\mathrm{o}}$ :

\begin{abstract}
As propostas pedagógicas da Educação Infantil deverão considerar que a criança, centro do planejamento curricular, é sujeito histórico e de direitos que, nas interações, relações e práticas cotidianas que vivencia, constrói sua identidade pessoal e coletiva, brinca, imagina, fantasia, deseja, aprende, observa, experimenta, narra, questiona e constrói sentidos sobre a natureza e a sociedade, produzindo cultura (BRASIL, 2013).
\end{abstract}

Assim, a organização do planejamento escolar para a educação deve ser elaborada seguindo as considerações trazidas na DCNEI, onde o uso das tecnologias deve ser pautado nos princípios descritos no artigo. Os primeiros anos de vida escolar representam a base para a formação de um sujeito crítico, participativo e ativo na sociedade, que saiba interagir e se relacionar adequadamente, apresentando atitudes de conhecimento e de valor.

No artigo $6^{\circ}$, as DCNEI tratam dos princípios a serem respeitados por meio das propostas de Educação Infantil, sendo de cunho ético, político e estético. Ético no sentido de liberdade, responsabilidade e respeito aos bens comuns da sociedade; político em relação aos direitos e deveres de todo o cidadão; e, estético, na representação das mais variadas manifestações culturais e artísticas. $\mathrm{O}$ art. $8^{\circ}$ traz o seguinte:

A proposta pedagógica das instituições de Educação Infantil deve ter como objetivo garantir à criança acesso a processos de apropriação, renovação e articulação de conhecimentos e aprendizagens de diferentes linguagens, assim como o direito à 
proteção, à saúde, à liberdade, à confiança, ao respeito, à dignidade, à brincadeira, à convivência e à interação com outras crianças (BRASIL, 2013, p.98).

Assim, entende-se que a criança tem o direito de acesso as mais variadas formas de conhecimento e aprendizagens científicas. Para tanto, a utilização de tecnologias educacionais por parte das instituições escolares conduz a ação de fomentar as práticas pedagógicas, por meio de atividades dinâmicas. É preciso salientar que na pré-escola, não se deve antecipar os conteúdos para as crianças, com o intuito de adiantar o processo formativo para a continuidade dos estudos no Ensino Fundamental, pois, ao avança-los, deixa-se de trabalhar com os conteúdos pertinentes e necessários para a Educação Infantil. Leia-se, na íntegra o Art. 11:

\footnotetext{
Na transição para o Ensino Fundamental a proposta pedagógica deve prever formas para garantir a continuidade no processo de aprendizagem e desenvolvimento das crianças, respeitando as especificidades etárias, sem antecipação de conteúdos que serão trabalhados no Ensino Fundamental (BRASIL, 2013, p. 100).
}

Logo, é fundamental a constância entre os processos de ensino-aprendizagem na transição da Educação Infantil para o primeiro ano do Ensino Fundamental, sendo necessário que "a nova etapa se construa com base no que os educandos sabem e são capazes de fazer, evitando a fragmentação e a descontinuidade do trabalho pedagógico" (BRASIL, 2018, p. 53). A ligação entre a Educação Infantil e os anos iniciais do Ensino Fundamental, sem rupturas, faz com que os conteúdos adquiridos em um primeiro momento sejam aprofundados e ampliados durante os primeiros anos do Ensino Fundamental.

Os primeiros anos do Ensino Fundamental, que atendem as crianças a partir dos 6 anos de idade, são de responsabilidade dos municípios, como disposto no Art. 11 da LDBEN 9.394/96, em seu inciso V: "oferecer a Educação Infantil em creches e pré-escolas e, com prioridade, o Ensino Fundamental” (BRASIL, 1996).

A partir disso, a BNCC (2018), estabelece que os anos iniciais devem reconhecer as situações lúdicas de aprendizagem, articulando-as com as vivências da Educação Infantil, a fim de progredir sistematicamente as experiências em relação ao desenvolvimento dos alunos, por meio das relações com o mundo da leitura, da escrita e das formulações de hipóteses sobre os acontecimentos da sociedade, gerando o conhecimento.

Os anos iniciais escolares promovem, na vida do estudante, significativas mudanças em seu processo de desenvolvimento, em suas relações de convivência e de apreensão do conhecimento de mundo. Os alunos começam a explorar sua autonomia e ampliam a rede de interações ao seu redor, portanto, "a afirmação de sua identidade em relação ao coletivo no qual se inserem resulta em formas mais ativas de se relacionarem com esse coletivo e com as normas que regem as relações entre as pessoas dentro e fora da escola", seja pela compreensão das diferenças ou pelo entendimento de suas potencialidades (BRASIL, 2018, p. 58).

Portanto, a escola precisa organizar-se para que a aplicação das tecnologias seja (mais) democrática, e que a participação dos sujeitos durante esse processo seja mais consciente, compreendendo a importância dessa implementação, uma vez que os alunos, inevitavelmente, já estão imersos na cultura digital (BRASIL, 2018). A inclusão das tecnologias no âmbito da escola do campo traz consigo novas perspectivas da inserção dos jovens no mundo da pesquisa, com um currículo formativo que propicie a manutenção das atividades do campo, tanto na prática como na teoria. 
Ao utilizar as facilidades dos meios digitais, a escola pode estabelecer diferentes formas de criar a interação, a aprendizagem e a disseminação de conhecimentos entre alunos e professores, por meio de dinâmicas, atividades em grupo e participação da comunidade escolar, explorando de maneira positiva as tecnologias educacionais presentes na sociedade contemporânea.

\section{Considerações finais}

Nos primeiros anos de alfabetização e vivência escolar, é de extrema importância criar um processo de aprendizagem que enfatize seus grupos de convivência e que possua interações com as mais variadas TDIC, possibilitando a formulação de perguntas, despertando a sua curiosidade e viabilizando o acesso ao conhecimento.

Todos os desafios delegados à escola, nos dias de hoje, refletem na formação das futuras gerações. Sendo assim, a instituição deve saber gerenciar os problemas, visando, no cumprimento de seu papel, estimular a reflexão e a observação dos alunos, colaborando para a constituição de um sujeito crítico frente aos desafios que irá enfrentar no futuro. Desse modo, o objetivo deste artigo foi o de refletir sobre o uso das tecnologias na educação do campo no município de Pitanga-PR, enfocando nos pontos críticos a esse respeito, tanto nas escolas rurais como nas urbanas.

É preciso entender que as tecnologias não são a solução de todos os problemas educacionais enfrentados no país e, especificamente nas escolas do campo, mas devem ser consideradas como uma excelente ferramenta de apoio na busca por soluções para a manutenção e permanências das atividades rurais que permeiam a comunidade local.

As instituições de ensino rurais devem considerar, no desenvolvimento de seus currículos, a identidade da região que atende e o uso de tecnologias, tanto na formação de professores, como no seu uso com os alunos, a fim de desenvolver e aprimorar os processos formativos de permanência no campo. Nem todas as instituições do país possuem acesso as novas tecnologias, em decorrência da falta de investimento e manutenção por parte do Estado, mas tem o dever de fazer, com o pouco que tem, muito, visando a melhoria da educação.

\section{Financiamento e agradecimentos}

O presente trabalho foi realizo com apoio da Coordenação de Aperfeiçoamento de Pessoal de Nível Superior - Brasil (CAPES) - Código de Financiamento 001.Vigência da bolsa de março 2019 a junho de 2020. Agradecimento especial ao Laboratório de estudos em Comunicação, Educação e Tecnologia (LECET/UNICENTRO).

\section{Referências}

ARROYO, Miguel Gonzalez; FERNANDES, Bernardo Mançano. A educação básica e o movimento social do campo. Brasília: articulação nacional por uma educação básica do campo, v. 2, 1999. Disponível em:

http://educampo.miriti.com.br/arquivos/Biblioteca/0081.pdf. Acesso em: 27 jul. 2019.

ARROYO, Miguel Gonzalez. Políticas de formação de educadores (as) do campo. Cadernos Cedes, Campinas, v. 27, n.72, p. 157-176, maio/ago. 2007. Disponível em: 
https://www.scielo.br/scielo.php?pid=S0101-

32622007000200004\&script=sci_arttext\&tlng=pt. Acesso em: 10 fev. 2020.

BRASIL. Lei n. 9.394. Estabelece as Diretrizes e Bases da Educação Nacional. Diário Oficial da União, Brasília, 20 de dezembro de 1996.

BRASIL. Ministério da Educação. Base Nacional Comum Curricular: Educação é a Base. Brasília: MEC, 2018.

BRASIL. Ministério da Educação. Diretrizes Curriculares Nacionais Para a Educação Básica. Brasília: SEB, 2013.

BRASIL. Lei n. 10.172, de 9 de janeiro de 2001: Plano Nacional de Educação. Disponível em: http://portal.mec.gov.br/arquivos/pdf/L10172.pdf. Acesso em: 12 set. 2020.

BRASIL. Lei n. 13.005, de 25 de junho de 2014. Plano Nacional de Educação. Disponível em:http://pne.mec.gov.br/18-planos-subnacionais-de-educacao/543-plano-nacional-deeducacao-lei-n-13-005-2014. Acesso em: 01 ago. 2019.

BRASIL. Constituição Federal de 1988. Constituição da República Federativa do Brasil de 1988. Brasília, 5 de outubro de 1988.

BRASIL. Emenda Constitucional $n^{\circ}$ 59, de 11 de novembro de 2009. Diário Oficial da União, Brasília, 12 de novembro de 2009. Disponível em:

<http://www.planalto.gov.br/ccivil_03/constituicao/Emendas/Emc/emc59.htm>. Acesso em: 01 ago. 2019.

CALDART, Roseli Salete. Educação do Campo: Notas para uma análise de percurso. Trabalho, educação e saúde, v. 7, n. 1, p. 35-64, 2009. Disponível em: https://www.scielo.br/scielo.php?pid=S1981-

77462009000100003\&script=sci_arttext\&tlng=pt. Acesso em: 02 abr. 2021.

CURY, Carlos R. Jamil. A educação básica como direito. Cadernos de pesquisa, v. 38, n. 134, p. 293-303, 2008. Disponível em: http://www.scielo.br/pdf/cp/v38n134/a0238134. Acesso em: 27 jul. 2019.

INSTITUTO NACIONAL DE ESTUDOS E PESQUISAS EDUCACIONAIS ANÍSIO TEIXEIRA. Sinopse Estatística da Educação Básica 2018. Brasília: Inep, 2019. Disponível em: http://portal.inep.gov.br/sinopses-da-educacao-basica. Acesso em: 30 jul. 2019.

MORAN, José Manuel. Ensino e aprendizagem inovadores com apoio de tecnologias. In: MORAN, José Manuel; MASETTO, Marcos T.; BEHRENS, Marilda Aparecida. Novas tecnologias e mediação pedagógica. 21. ed. rev. e atual. - Campinas, SP: Papirus, 2013. Coleção Papirus Educação.

PROJETO POLÍTICO PEDAGÓGICO. Escola Municipal do Campo Sagrada Família. Pitanga/PR, 2019. 
SANT’ANA, Edite; BEHRENS, Marilda Aparecida. Superação dos Paradigmas conservadores na Sociedade do Conhecimento. In: BEHRENS, Marilda Aparecida. (org.) Docência Universitária na Sociedade do Conhecimento. Curitiba: Champagnat. 2003.

SILVA, Rodrigo Abrantes da; CAMARGO, Ailton Luiz. A cultura escolar na era digital: O impacto da aceleração tecnológica na relação professor-aluno, no currículo e na organização escolar. In: BACICH, Lilian; NETO, Adolfo Tanzi; TREVISANI, Fernando de Mello (org). Ensino Híbrido: personalização e tecnologias na educação. Porto Alegre: Penso, 2015.

VALENTE, José Armando. Mudanças na sociedade, mudanças na Educação: o fazer e o compreender. In: VALENTE, José Armando (org.). O computador na Sociedade do Conhecimento. Campinas, SP: UNICAMP/NIED, 1999.

VALENTE, José Armando. A comunicação e a Educação baseada no uso das Tecnologias da Informação e Comunicação. Revista UNIFESO: Humanas e Sociais. v. 1, n. 1, 2014, p. 141166. Disponível em:

http://www.revista.unifeso.edu.br/index.php/revistaunifesohumanasesociais/article/view/17/2 4. Acesso em: 20 nov. 2019.

VALENTE, José Armando. Blended learning e as mudanças no ensino superior: a proposta da sala de aula invertida. Educar em revista, n. 4, p. 79-97, 2014. Disponível em: https://www.redalyc.org/pdf/1550/155037796006.pdf. Acesso em: 30 nov. 2019.

VIGHI, Cátia Simone Becker. Formação docente: a educação do campo em foco. Formação Docente, Belo Horizonte, v.7, n. 13, p. 115-132, ago./dez. 2015. Disponível em:

https://revformacaodocente.com.br/index.php/rbpfp/article/view/126/115. Acesso em: 01 out. 2019. 